\title{
CORRELAÇÃO GENÉTICA, FENOTÍPICA E AMBIENTAL EM CARACTERÍSTICAS DE CRESCIMENTO DE BOVINOS DA RAÇA NELORE VARIEDADE MOCHA*
}

\section{(Genetic, phenotypic and environmental correlation in the growth traits in bovines of the polled nellore breed)}

\author{
SANTOS, P.F.'; MALHADO, C.H.M.M. ${ }^{2}$ CARNEIRO, P.L.S. ${ }^{3}$; MARTINS FILHO, R. ${ }^{3}$; \\ AZEVÊDO, D.M.M.R. ${ }^{4}$; CUNHA, E.E. ${ }^{5}$; SOUZA, J.C. ${ }^{6}$; FERRAZ FILHO, P.B. ${ }^{7}$
}

\author{
'Graduanda UESB - Jequié-BA; \\ ${ }^{2}$ Professor DCB/UESB - Av: José Moreira Sobrinho, S/N, Jequiezinho, Jequié-BA, CEP: 45200-000 \\ malhado@uesb.br; pcarneiro@uesb.br; \\ ${ }^{3}$ Pesquisador UFPI, Bolsista CNPq, rmartinsfilho@yahoo.com.br; \\ ${ }^{4}$ Pesquisadora Embrapa Meio Norte, azevedo@cpamn.embrapa.br; \\ ${ }^{5} \mathrm{UFV}$; \\ ${ }^{6}$ Campus Palotina/UFPR, jcs@ufpr.br; \\ 7Professor DCN/UFMS, pferraz@ceul.ufms.br.
}

\begin{abstract}
RESUMO - O objetivo deste trabalho foi estimar as correlações genéticas, fenotípicas e ambientais sobre os pesos ao nascimento (PN) e aos 205 (P205), 365 (P365) e 550 (P550) dias de idade, em animais da raça Nelore Mocha, criados no estado da Bahia. As análises bi-características foram realizadas através do programa MTDFREML. As correlações genéticas foram iguais a 0,08 (PN e P205), 0,00 (PN e P365), - 0,14 (PN e P550), 0,90 (P205 e P365), 0,81, (P205 e P550) e 0,97 (P365 e P550). As correlações ambientais foram 0,12 (PN e P205), 0,11 (PN e P365), 0,16 (PN e P550), 0,35 (P205 e P365), 0,13 (P205 e P550) e 0,54 (P365 e P550). Os valores obtidos para as correlações fenotípicas foram 0,09 (PN e P205), 0,05 (PN e P365), 0,00 (PN e P550), 0,75 (P205 e P365) 0,65 (P205 e P550) e 0,87 (P365 e P550). O peso ao nascimento apresentou ausência de associações genéticas, ambientais e fenotípicas com as demais pesagens. Por outro lado, os valores obtidos para as correlações genéticas entre as outras pesagens, indicam que a seleção para peso em idades jovens deverá promover mudanças nos pesos posteriores dos animais.
\end{abstract}

Palavras-Chave: Análise bi-característica, parâmetro, peso, seleção.

\begin{abstract}
The objective of this work was estimate the genetic correlations, environmental and phenotypic on the birth weight (WB) and on the 205 (W205), 365 (W365) and 550 (W550) days of age, in animals of the polled nellore breed from Bahia state. The analyses were carried out by software MTDFREML. The genetic correlations were 0.08 (WB and W205), 0.00 (WB and W365), 0.14 (WB and W550), 0.90 (W205 and W365), 0.81 (W205 and W550) and 0.97 (W205 and W550). The environmental correlations were 0.12 (WB and W205), 0.11 (WB and W365) and 0.16 (WB and W550), 0.35 (W205 and W365), 0.13 (W205 and W550) and 0.54 (W365 and W550). The phenotypic correlations were 0.09 (WB and W205), 0.05 (WB and W365), 0.00 (WB and W550), 0.75 (W205 and W365), 0.65 (W205 and W550) and 0.87 (W365 and W550). The birth weight presented weak genetic, environmental, and phenotypic associations with the others weighting. On the other hand, the values gotten for the genetic correlations between the other weighting, indicates that the selection for weight in young ages will promote changes on the future weights of the animal.
\end{abstract}

Key-words: analyze two-traits, parameter, selection, weight.

\footnotetext{
*Apoio CNPq e PAGAB (Programa de Avaliação Genética Animal da Bahia).
} 


\section{Introdução}

Vários são os estudos sobre o crescimento de bovinos de corte, e esses mostram uma grande variação quanto às médias das diferentes características. Tal variação ocorre, principalmente, em função das diferenças genéticas, nutricionais e do manejo em geral, que variam entre regiões e fazendas, além dos diferentes objetivos de seleção utilizados no país (MALHADO et al., 2002).

$\mathrm{Na}$ elaboração de programas de seleção, no entanto, é imprescindível o conhecimento dos fatores que influenciam o crescimento dos animais, bem como, das correlações genéticas entre eles, pois esses parâmetros genéticos constituem elementos básicos para o estabelecimento de diretrizes que possam orientar o melhoramento genético dos animais (OLIVEIRA et al., 1993).

Estatisticamente, correlação pode ser definida como a dependência entre as funções de distribuição de duas ou mais variáveis aleatórias, em que a ocorrência de um valor de uma das variáveis favorece a ocorrência de um conjunto de valores das outras. As correlações entre duas ou mais características estimam o nível de união entre elas, sendo a origem e a grandeza da relação existente entre as características de grande importância no melhoramento em geral, pois visam aprimorar o material genético de um conjunto de caracteres que agem simultaneamente; conseqüentemente, a melhora de uma característica pode causar alterações nas demais (FALCONER, 1987).

A associação entre duas características que pode ser observada diretamente é a correlação de valores fenotípicos, ou a "correlação fenotípica". Em estudos genéticos, é necessário distinguir duas causas de correlação entre características, a genética e ambiental. $O$ tamanho e o sentido das respostas correlacionadas são determinados, principalmente, pela correlação genética entre as características envolvidas.

A causa de correlação genética é, principalmente, pleiotropismo, embora ligações gênicas sejam causa de correlação transitória, especialmente em populações originadas de cruzamentos entre linhagens divergentes
(FALCONER, 1987). A pleiotropia define o processo em que um mesmo gene pode afetar duas ou mais características, ou seja, o grau de correlação originado expressa a intensidade pela qual duas características são influenciadas pelos mesmos genes.

Do ponto de vista do melhoramento genético, a conseqüência da correlação genética é que se duas características economicamente importantes evidenciam correlação altamente positiva, a ênfase na seleção poderá ser endereçada para uma, visando o melhoramento de ambas, além da seleção indireta para características de difícil mensuração e/ou características que se expressam tardiamente no animal. Entretanto, se existe uma correlação negativa entre duas características, a seleção para uma delas, proporcionará mudanças em outro sentido na outra.

O ambiente é uma causa de correlação pela qual duas características são influenciadas pelas mesmas diferenças de condições de ambiente. A correlação de ambiente, não é, estritamente falando, a correlação dos desvios de ambiente, mas a correlação conjunta de desvios de ambiente e desvios genéticos não aditivos.

Vários autores, estudando raças zebuínas, determinaram as correlações fenotípicas, genéticas e de ambiente entre pesos em diferentes idades. Nestes estudos, os autores encontraram valores elevados de correlações para características de crescimento, sugerindo que a maioria dos genes com efeitos aditivos e que a maior parte dos efeitos ambientais que favorecem uma característica também favorecem outras (OLIVEIRA et al., 1993; MASCIOLI et al., 1995; FERRAZ FILHO, 1996; MARTINS et al., 1998; BIFFANI et al., 1999a,b; FERRAZ FILHO et al. 2002 e MALHADO et al. 2002).

Apesar do número razoável de estimativas dos parâmetros genéticos, fenotípicos e ambientais para as diferentes pesagens no Brasil, deve-se salientar que são raros os estudos registrados na literatura com enfoque na bovinocultura de corte do Nordeste. Isso representa uma grande limitação, já que o conhecimento das estimativas de herdabilidade, das correlações genéticas e ambientais e das fontes de variações não- 
Correlação genética, fenotípica e ambiental em características de crescimento de bovinos da raça nelore...

genéticas é essencial em qualquer programa de melhoramento animal.

Esses parâmetros são próprios da população avaliada e pelo conhecimento pode-se alterar através da seleção e de adequação de métodos de criação (KOOTS et al., 1994). Assim, é objetivo deste estudo estimar as correlações genéticas, fenotípicas e ambientais sobre os pesos ao nascimento e aos 205, 365 e 550 dias de idade, em animais da raça Nelore Mocha, criados no estado da Bahia.

\section{Material e Métodos}

Os dados utilizados neste estudo foram provenientes do controle de desenvolvimento ponderal da raça Nelore, da Associação Brasileira dos Criadores de Zebu (ABCZ), de animais criados a pasto, nascidos no período de 1975 a 2003, no estado da Bahia. Foram utilizadas informações de pesagens de 1.457 animais, com 2.560 animais na matriz de parentesco.

Para obter as estimativas das (co)variâncias, empregou-se a metodologia da Máxima Verossimilhança Restrita Livre de Derivada (DFREML), por meio de modelo animal bicarater, utilizando o aplicativo Multiple Traits
Derivate Free Restrict Maximum Likelihood (MTDFREML), desenvolvido por BOLDMAN et al. (1995). O critério de convergência adotado foi $10^{-9}$. A cada convergência o programa era reiniciado, utilizando como valores iniciais àqueles obtidos na análise anterior, até que o valor $-2 \log L$ não se reduzisse mais, alcançado a convergência global.

O modelo continha o efeito aleatório aditivo direto, e o efeito fixo de grupo de contemporâneos (fazenda - seis, sexo, estação e ano de nascimento do animal).

Para a formação dos grupos contemporâneos (268) foram consideradas quatro estações de nascimento: janeiro a março, abril a junho, julho a setembro e outubro a dezembro.

\section{Resultados e Discussão}

As médias observadas para os pesos ao nascimento e aos 205, 365 e 550 dias de idade foram 30,76, 168,93, 237,49 e $321,97 \mathrm{~kg}$, com coeficientes de variação de 11,38, 17,52, 20,80 e $23,17 \%$, respectivamente.

As correlações genéticas, ambientais e fenotípicas entre as pesagens estão apresentadas nas TABELAS 1 e 2.

TABELA 1 - CORRELAÇÕES FENOTÍPICAS a E AMBIENTAIS ${ }^{\circ}$ DOS PESOS AO NASCIMENTO (PN), AOS 205 DIAS (P205), AOS 365 DIAS (P365) E AOS 550 DIAS (P550) DE IDADE, DE BOVIMOS DA RAÇA NELORE MOCHA.

\begin{tabular}{lcccc}
\hline & $P N$ & $P 205$ & $P 365$ & $P 550$ \\
\hline PN & - & 0,09 & 0,05 & 0,00 \\
P205 & 0,12 & - & 0,75 & 0,65 \\
P365 & 0,11 & 0,35 & - & 0,87 \\
P550 & 0,16 & 0,13 & 0,54 & - \\
\hline
\end{tabular}

${ }^{a}$ Acima de diagonal, ${ }^{b}$ Abaixo da diagonal

TABELA 2 - CORRELAÇÕES GENÉTICAS DOS PESOS AO NASCIMENTO (PN), AOS 205 DIAS (P205), AOS 365 DIAS (P365) E AOS 550 DIAS (P550) DE IDADE, DE BOVINOS DA RAÇA NELORE MOCHA.

\begin{tabular}{lcccc}
\hline & $P N$ & $P 205$ & $P 365$ & $P 550$ \\
\hline PN & - & 0,08 & 0,00 & $-0,14$ \\
P205 & & - & 0,90 & 0,81 \\
P365 & & & - & 0,97 \\
P550 & & & - \\
\hline
\end{tabular}


Os valores obtidos para as correlações genéticas entre o peso ao nascimento e as outras pesagens foram $0,08,0,00$ e - 0,14 , com P205, P365 e P550, respectivamente. Valores superiores foram relatados por FERRAZ FILHO (1996), com estimativas das correlações genéticas do peso ao nascimento de 0,42, 0,47 e 0,51, com P205, P365 e P550, em bovinos da raça Nelore variedade mocha.

Já as correlações fenotípicas foram 0,09; 0,05 e 0,03, para PN e P205; PN e P365; PN e P550, respectivamente. Já FERRAZ FILHO (1996) estimou valor de 0,15 , para o peso ao nascimento, com as outras três pesagens.

As correlações ambientais encontradas entre PN e P205; PN e P365, PN e P550 foram 0,12; 0,11 e 0,16 , respectivamente. Correlações inferiores foram estimadas por FERRAZ FILHO (1996), com valores de 0,04, -0,02 e -0,10, de PN com P205, P365 e P550, respectivamente. ROSA et al. (1986), estudando bovinos da raça Nelore, também relataram correlação negativa $(-0,07)$ entre PN e P365. Segundo FERRAZ FILHO (1996) as baixas correlações de ambiente, indicam pequena associações genética aditiva e/ou ambiental entre o peso ao nascimento e às idades superiores.

É evidente a fraca associação do peso ao nascimento com as outras características. De acordo com MALHADO et al. (2004), o peso ao nascimento apresenta uma distribuição com marcada discrepância da distribuição normal, visto que, na prática, muitas vezes os animais recém-nascidos são pesados em balanças irregularmente instaladas, ou até mesmo, em balanças de varas, geralmente imprecisas e, em alguns casos, esse peso é até subjetivamente registrado pelo funcionário, fato que compromete a distribuição dos dados, implicando em presença de víeis. Desta forma as análises estatísticas e/ ou genética envolvendo o peso ao nascimento podem ser prejudicadas pela qualidade da pesagem e conseqüentemente pela distribuição irregular da característica.

A correlação genética entre P205 e P365 foi de 0,90 , mostrando que grande partes dos genes que atuam no peso aos 205 dias, atuam também aos 365 dias de idade. As estimativas obtidas neste estudo foram superiores aos valores apresentados por BIFFANI et al. (1998): 0,81; FERRAZ FILHO et al. (2002): 0,81 e
MALHADO et al. (2002): 0,75, para as raças Nelore, Tabapuã e Guzerá, respectivamente. Já a correlação fenotípica entre as duas pesagens foi 0,75 , valor superior às obtidas nos trabalhos de BIFFANI et al. (1998): 0,65; FERRAZ FILHO et al. (2002): 0,49 e MALHADO et al. (2002): 0,59. A correlação ambiental foi de 0,35 , sendo inferior aos valores de animais zebuínos apresentados por NÁJERA - AYALA et al. (1991): 0,94 (Nelore), FERRAZ FILHO (1996): 0,61; BIFFANI et al. (1998): 0,59 e MALHADO et al. (2002):0,44.

A correlação genética entre P205 e P550 foi 0,81 , evidenciando a importância da seleção em idades mais jovens. Resultados inferiores foram relatados por FERRAZ FILHO (1996) que ao revisar a literatura obteve media de correlação genética de 0,62 , para animais Nelore e por MALHADO et al. (2002): 0,61, entretanto, valores semelhantes foram encontrados por BIFFANI et al. (1998): 0,80 e FERRAZ FILHO et al. (2002): 0,83 e valor superior foi obtido por SILVEIRA et al. (2000):0,86, estudando a raça Nelore.

A correlação fenotípica estimada entre essas características foi 0,65 , valor superior aos trabalhos de MALHADO et al. (2002): 0,42; BIFFANI et al.(1998):0,52 e FERRAZ FILHO et al. (2002): 0,53. A estimativa da correlação de ambiente $(0,13)$ foi inferior aos trabalhos de FERRAZ FILHO (1996): 0,51; BIFFANI et al. (1998): 0,40 e MALHADO et al. (2002): 0,39.

A correlação genética de 0,97 estimada para os pesos aos 365 dias e aos 550 dias de idade foi superior a media $(0,84)$ citada por FERRAZ FILHO (1996). O valor obtido para a correlação genética entre estes pesos, também foi superior aos obtidos por BIFFANI et al. (1998): 0,90; FERRAZ FILHO et al. (2002): 0,82 e MALHADO et al. (2002): 0,65.A correlação fenotípica $(0,87)$ encontrada entre estes pesos é superior a encontrada por BIFFANI et al. (1998): 0,65 e por MALHADO et al. (2002): 0,65 . A correlação de ambiente $(0,54)$ foi inferior aos trabalhos de FERRAZ FILHO et al. (2002): 0,58; MILAGRES et al. (1985): 0,63; MALHADO et al. (2002): 0,66 e SILVA et al. (1987): 0,70, entretanto semelhante ao resultado apresentado por BIFFANI et al. (1998): 0,55.

Os menores valores para as correlações ambientais neste estudo provavelmente são 
Correlação genética, fenotípica e ambiental em características de crescimento de bovinos da raça nelore...

devido às condições climáticas discrepantes e adversas entre os diferentes meses e anos na região Nordeste. Também, deve ser ressaltado que o efeito materno não foi incluído no modelo de análise, sendo o efeito materno modelado conjuntamente com os efeitos ambientais. Assim, este efeito influenciou em maior magnitude o peso ao desmame em relação aos pesos aos 365 e 550 dias de idade.

As correlações genéticas e de ambiente são, freqüentemente, muito diferentes em magnitude, e, algumas vezes, diferentes em sinal.Uma diferença deste tipo entre as duas correlações mostra que as causas de variação genéticas e de ambiente afetam os caracteres por meio de diferentes mecanismos fisiológicos (FALCONER, 1987).

$\mathrm{Em}$ os todos os casos analisados, a correlação genética entre P205 e P365, P205 e P550, e P365 e P550 foram superiores em magnitude à fenotípica. Isto, a primeira vista parece improvável, pois a fenotípica contém a genética. Entretanto, SEARLE (1961) demonstrou que as correlações fenotípicas podem ser de menores magnitudes que as genéticas, quando os genes que controlam duas características quaisquer são similares, porém, com correlações ambientais baixas e positivas entre as características.

\section{Conclusões}

O peso ao nascimento apresentou fracas associações genéticas, ambientais e fenotípicas com as outras pesagens.

As correlações genéticas e fenotipicas entre P205, P365 e P550 foram de alta magnitude e superiores as correlações ambientais entre estas características, indicando que a seleção para qualquer uma delas trará ganhos nas outras.

\section{REFERÊNCIAS}

BIFFANI, S.; MARTINS FILHO, R.; BOZZI, R.; LIMA, F.A.M. Parâmetros genéticos e fenotípicas para características de crescimento em animais de raça Nelore. In: REUNIÃO ANUAL DA SOCIEDADE BRASILEIRA DE ZOOTECNIA, 35., 1998, Botucatu. Anais... Botucatu: SBZ, 1998. CD-ROM.
BIFFANI, S.; MARTINS FILHO, R.;GIORGETTI, A., BOZZI, R., LIMA, F.A.M. Fatores ambientais e genéticos sobre o crescimento ao ano e ao sobreano de bovinos Nelore, criados no Nordeste do Brasil. Revista da Sociedade Brasileira de Zootecnia, Viçosa, v. 28, n. 4, p. 468-473, 1999a.

BIFFANI, S.; MARTINS FILHO, R.;MARTINI, A. BOZZI, R. : LIMA, F.A.M. Fatores ambientais e genéticos que influenciam o desenvolvimento ponderal até o desmame de animais Nelore criados no Nordeste do Brasil. Revista da Sociedade Brasileira de Zootecnia, Viçosa, v. 28, n. 4, p. 693-700, 1999b.

BOLDMAN, K.G.; KRIESE, L.A.; VAN VLECK, L.D. A Manual for Use of MTDFREML; a Set of Programs to Obtain Estimates of Variances and Covariances [DRAFT]. Lincoln: Department of Agriculture, Agricultural Research Service, 1995. 120 p.

FALCONER, D.S. Introdução à genética quantitativa. Viçosa: UFV, 1987. 279 p.

FERRAZ FILHO, P.B. Análise e tendência genética de pesos em bovinos da raça Nelore mocha no Brasil. Jaboticabal, 1996. 163f. Dissertação (Mestrado) Universidade Estadual Paulista.

FERRAZ FILHO, P.B.; RAMOS, A.A.; SILVA, L.O.C.; SOUZA, J.C.; ALENCAR, M.M. Herdabilidade e correlações genéticas, fenotípicas e ambientais para pesos em diferentes idades de bovinos da raça Tabapuã. Archives of Veterinay Science, Curitiba, v. 7, n. 1, p. 65-69, 2002.

KOOTS, K.R.; GIBSON, J.P.; WILTON, J.W. Analyses of published genetic parameters estimates for beef production traits. 1. Heritability. Animal Breeding Abstract, v. 62, n. 5, p. 309-338, 1994.

MALHADO, C.H.M.; SOUZA, J.C.; SILVA, L.O.C.; FERRAZ FILHO, P.B. Correlação genéticas, fenotípicas e de ambiente entre os pesos da várias idades em bovinos da raça Guzerá no Estado de São Paulo. Archives of Veterinary Science, Curitiba, v. 7, n. 1, p. 71-75, 2002.

MALHADO, C.H.M; CARNEIRO, P.L.S.; MARTINS FILHO, R.; AZEVEDO, D.M.M.R.; SANTOS, P.F.; SOUZA, J.C.; FACÓ, O. Análise das pesagens de Indubrasil na Bahia. IN: CONGRESSO NORDESTINO DE PRODUÇÂO ANIMAL, 3., Campina Grande, 2004. Anais... Campina Grande: SNPA, 2004. CD-ROM.

MARTINS, G.A.; MARTINS FILHO, R.; LIMA, F.A.M.; LÔBO, R.N.B. Influencias de fatores genéticos e de meio sobre o crescimento de bovinos da raça Nelore no Estado do Maranhão. In: REUNIÃO ANUAL DA SOCIEDADE BRASILEIRA DE ZOOTECNIA, 35., 1998, Botucatu. Anais... Botucatu: SBZ, 1998. p. 431-433. 
MASCIOLI, A.S.; ALENCAR, M.M.; BARBOSA, P.F. Estimativas de parâmetros genéticos e fenotípicas para pesos na raça Canchim. In: REUNIÃO ANUAL DA SOCIEDADE BRASILEIRA DE ZOOTECNIA, 32., 1995, Brasília. Anais... Brasília: SBZ, 1995. p. 623624.

MILAGRES, J.C.; SILVA, L.O.C.; NOBRE, P.R.C.; ROSA, A.N. Influencia de fatores de meio e herança sobre pesos de animais da raça Nelore no Estado de Minas Gerais. Revista da Sociedade Brasileira de Zootecnia, Viçosa , v. 14, p. 463-84, 1985.

NÁJERA-AYALA, J.M.; PEREIRA, J.C.C.; OLIVEIRA, H.N. Efeitos genéticos e não genéticos sobre características ponderais de duas populações da raça Nelore. Arquivo Brasileiro de Medicina Veterinária e Zootecnia, Belo Horizonte, v. 43, n. 1, p. 8191, 1991.

Recebido para publicação: 28/05/2005

Aprovado: $20 / 10 / 2005$
OLIVEIRA, J.A.; LOBO, R.B.; GONÇALVES, A.A.M. Estimativas de parâmetros genéticos e fenotípicas de pesos e ganho em peso do nascimento aos 365 dias de idade em um rebanho da raça Guzerá. Boletim de Industria Animal, São Paulo, v. 50, p. 119-123, 1993.

SEARLE, S.R. Variance components in the unbalanced 2-way nested classification. Annals of Mathematical Statistics, Hayward, v. 32, p. 1161-1166, 1961.

SILVA, L.O.C.; ROSA, A.N.; NOBRE, P.R.C. Analise de pesos de bovinos Nelore, criados a pasto no Estado de São Paulo, Brasil. Pesquisa Agropecuária Brasileira, Brasília, v. 22, n. 11/12, p. 1245-1246, 1987.

SILVEIRA, J.C.; SOUZA, A.P.; MANUS, C.; SILVEIRA, A.C. Parâmetros genéticos e ambientais de características produtivas em animais da raça Nelore no Mato Grosso do Sul. In: REUNIÃO DA SOCIEDADE BRASILEIRA DE ZOOTECNIA, 37., 2000, Viçosa. Anais... Viçosa:SBZ, 2000. CD-ROM. 